\title{
THE ACTIVE SUSPENSION SYSTEM WITH HYDRAULIC ACTUATOR FOR HALF CAR MODEL ANALYSIS AND SELF-TUNING WITH PID CONTROLLERS
}

\author{
E.Venkateswarulu ${ }^{1}$, N. Ramesh raju ${ }^{2}$, G.Seshadri $^{3}$ \\ ${ }^{1}$ PG Student, Dept of EEE, Siddhartha Institute of Engineering. And Technology, Andhra Pradesh, India. \\ ${ }^{2}$ Asst Professor, Dept of EEE, Siddhartha Institute of Engineering. And Technology, Andhra Pradesh, India \\ ${ }^{3}$ Associate Professor, Dept of EEE, Siddhartha Institute of Engineering. And Technology, Andhra Pradesh, India
}

\begin{abstract}
In this paper design of active suspension in a half car model is presented. The idea of suspension has to improve the ride quality while maintaining good handling characteristics of three road distrubancences bump and hole, sine and random .it input have been applied to disturb the suspension system. Then PID controller for active suspension system of half car model has been simulated by using an analytical model within MATLAB SIMULINK software. Based on these three road disturbances, the performances of passive and active suspension system were investigated.
\end{abstract}

Keywords: active suspension system, PID controller, heuristic, Ziegler Nichols, iterative learning algorithm.

\section{INTRODUCTION}

The basic function of the vehicle suspension is to provide comfort to passengers, maximize the friction between the tires and the road surface and provide steering stability with good handling. In order to improve handling and comfort performance the suspension system should have its own mechanism which gives a great comfort and safety for driver and passengers inside the vehicle especially when the vehicle hitting a bump or a hole and also due to cornering. So In order to had the best performance of suspension several characteristics which deal with the regulation of the vehicle half car body and suspension movements, and also the force distribution must be considered [1], [2].

the vehicle's ride quality has been conducted and improvement have been achieved [3]. Kaleemullah has investigated active suspension system which involved development of three controllers for namely half car model robust H, Fuzzy and LQR controllers [4].taking on the on Kruczek (2011), H-infinity is another controller that has been used for active suspension system which plays an important part for car comfort and safety referring [5].the Intelligent controllers such as adaptive neural network [6], fuzzy logic [7] and fuzzy skyhook [8] have been implemented into the active system .PID intelligent technique used for tuning purposes in this system [9].

\subsection{Analyzing of Vehical Raid Model}

The active suspension of hydraulic system physical layout for half car model having rear tire shown in figure 1 - ***.

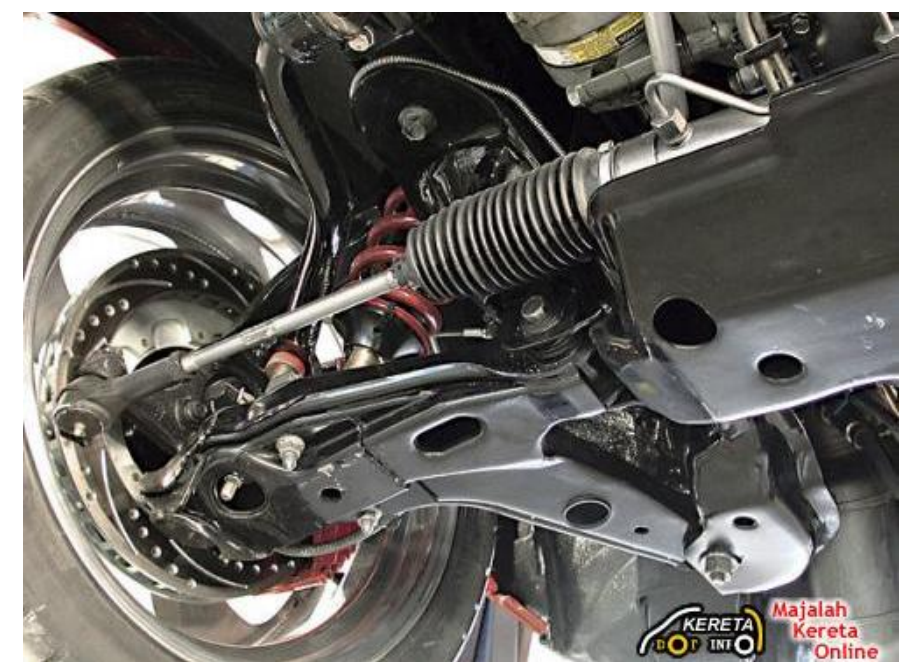

Fig 1 Suspension system physical layout for half car model rear tire

A half car model with four degree of freedom can be used to represent the pitch motion of the vehicle without considering the roll vibration models. Figure 1 shows the half car model for active suspension system

Using Newton's second law, the equation motions of half car model are: 


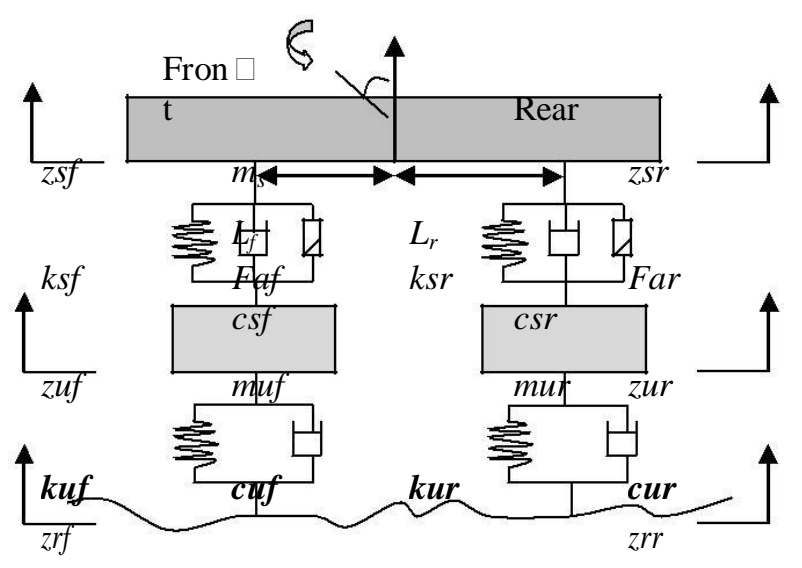

Fig 2 Half car model for active system

$$
\text { Ffront }=k s f(z u f-z s f-l \dot{\theta})+\operatorname{cs} f(\dot{Z} u f-\dot{Z} s f-
$$
$l \theta$

$$
\begin{aligned}
& \text { Frear }=k s r(z u r-z s r+l \dot{\theta})+\operatorname{csr}(\dot{Z} u r-\dot{Z} s r+ \\
& l \dot{\theta})
\end{aligned}
$$

where $\mathrm{k}$ sf and $\mathrm{ksr}$ are front and rear suspension spring stiffness, csf and csr are front and rear damping rate, zuf and zur are front and rear vehicle distance unsprung, $\theta$ is pitch angle, $l$ is distance from front and rear system and $\mathrm{ms}$ is a body mass. Faf and Far represent for the front and rear actuator force respectively. Thus, the pitch moment in body motion is:

$$
\underset{\text { Iyy } \ddot{\theta}}{(\text { Ffront }- \text { Faf }}) L f+(\text { Frear }- \text { Far }) L r=
$$

$L_{f}$ and $L_{r}$ are the front and rear displacements from body center gravity and $I_{y y}$ is the body moment of total inertia about gravity center. The transfer function of actuator is required to be obtained between actuation force and displacement as output and input respectively. The inverse transfer function can be modeled bellow.be cause of To overcome this problem, the inverse transfer function was obtained using the simplest system identification method utilizing least square (LS) method [11].

$$
\begin{gathered}
G p=\frac{\text { Displacement_output }}{\text { Actuation_force }} \\
\mathrm{Gp}=\frac{\left((m s-m u s) s^{2}+c u s+k u s\right)}{\left(\begin{array}{c}
(m s m u s) s^{4}+(c s m u s+m s c s+m s c u s) s+ \\
(m u s+c s c u s+k s m s+m s k u s) s^{2}+(k u s+k s c u s) s+k s k u s
\end{array}\right)}
\end{gathered}
$$

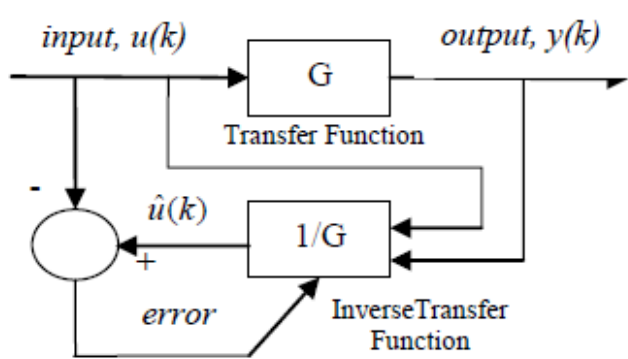

Fig 3 Block diagram of inverse transfer function model structure

The input and output data between actuation force and displacement were acquired using the Xiaming's transfer function. Using autoregressive with exogenous terms ARX Linear model structure, the main parameters for the inverse transfer function were obtained. The block diagram of model structure can be represented as on above the Figure 2. Using least square technique with ARX structure model order $=2$, the inverse transfer function can be modeled as in equation (6).

$$
u(k)=\frac{\left(b 1^{-1}+b 2^{-2}\right)}{\left(1+a 1 q^{-1}+a 2 q^{-2}\right)} y(k)
$$

\section{MODELLING AND CONTROL OF SUSPENSION SYSTEM}

\subsection{Disturbances Input}

There are Three types of road profile input disturbance were introduced to excite the system which are figure bump and hole, sine wave and random input. The first input disturbance introduced as the road profile is the bump and hole which represent a vehicle motion when hitting a hole of $0.1 \mathrm{~m}$ height and hole of $0.1 \mathrm{~m}$ depth as shown in Figure 4(a). The second type of disturbance is sinusoidal input with amplitude of $0.1 \mathrm{~m}$ and frequency of $4 \mathrm{~Hz}$ as shown in Figure 4(b). The final disturbance input is the random road profile as shown in Figure 4(c).

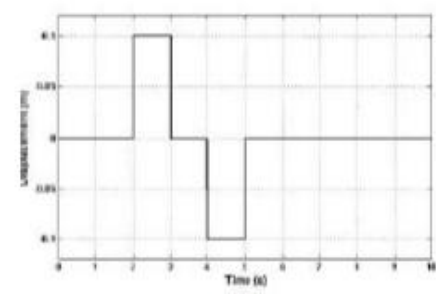

(a)

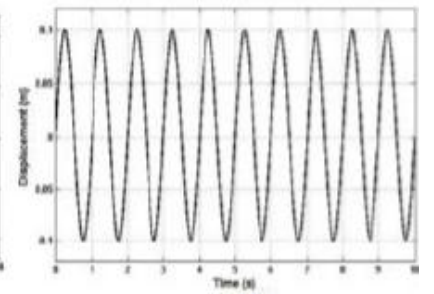

(b)

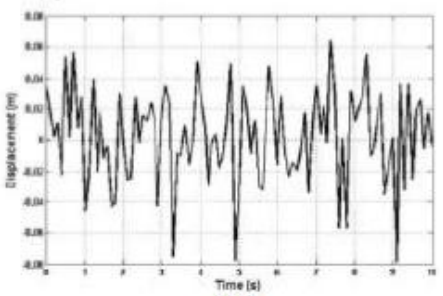

(s)

Fig 4 Displacement for (a) bump and hole, (b) sinusoidal, and (c) for random input road profile 


\subsection{Design PID Controller}

Proportional - Integral - Derivative (PID) controller was designed to control the feedback of the system effectively as well as to ensure the error of the output can be reduced efficiently [8]. In this study, PID controller as shown in Figure 4 was designed to ensure the output displacement of the system can be controlled and the displacement can be minimized when the disturbance occurs.

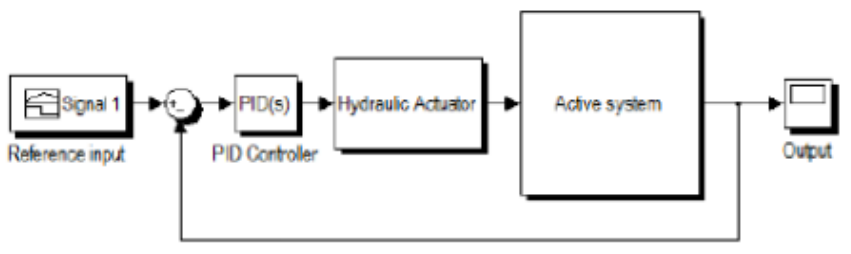

Fig 5 PID controller design

The parameters of the half car model system used in this paper are as shown in Table 1.

Table 1 Parameters of half car model

\begin{tabular}{|l|l|l|}
\hline Descriptions displacement & Symbols & Values \\
\hline $\begin{array}{l}\text { Front } \\
\text { from CG }\end{array}$ & Lf & $1.1 \mathrm{~m}$ \\
\hline $\begin{array}{l}\text { Rear displacement from } \\
\text { CG }\end{array}$ & Lr & $1.5 \mathrm{~m}$ \\
\hline Body mass & $m s$ & $1080 \mathrm{~kg}$ \\
\hline Body moment of inertia & Iyy & $\begin{array}{l}210000 \\
\mathrm{kgm}\end{array}$ \\
\hline $\begin{array}{l}\text { Front suspension } \\
\text { stiffness }\end{array}$ & $k s f$ & $\begin{array}{l}160000 \\
\mathrm{~N} / \mathrm{m}\end{array}$ \\
\hline $\begin{array}{l}\text { Rear tire } \\
\text { stiffness }\end{array}$ & $k s r$ & $\begin{array}{l}160000 \\
\mathrm{~N} / \mathrm{m}\end{array}$ \\
\hline $\begin{array}{l}\text { Front } \\
\text { stiffness }\end{array}$ & $k u f$ & $\begin{array}{l}160000 \\
\mathrm{~N} / \mathrm{m}\end{array}$ \\
\hline Rear tire spring stiffness & $k u r$ & $\begin{array}{l}160000 \\
\mathrm{~N} / \mathrm{m}\end{array}$ \\
\hline Front damping rate & $c s f$ & $\begin{array}{l}1500 \\
\mathrm{~N}(\mathrm{~m} / \mathrm{s})\end{array}$ \\
\hline Rear damping rate & $c s r$ & $\begin{array}{l}1500 \\
\mathrm{~N}(\mathrm{~m} / \mathrm{s})\end{array}$ \\
\hline Front tire damping rate & cuf & $\begin{array}{l}150 \\
\mathrm{~N}(\mathrm{~m} / \mathrm{s})\end{array}$ \\
\hline Rear tire damping rate & cur & $\begin{array}{l}150 \\
\mathrm{~N}(\mathrm{~m} / \mathrm{s})\end{array}$ \\
\hline
\end{tabular}

\subsection{Inverse Model of Hydraulic Actuator}

As described earlier, the inverse transfer function of the hydraulic actuator was obtained using system identification method utilizing least square estimation. The ARX model structure with model order 2 was used to represent the estimated actuator model. Figures 5 and 6 show the least estimated actuator model. Figures 5 and 6 show the least square estimation output of the inverse transfer function in comparison with the actual value and prediction error, respectively.

$$
\frac{y(s)}{u(s)}=\frac{0.0012 s^{2}-0.001 s-0.0002}{0.0003 s^{2}-0.9991 s-0.0006}
$$

The mean square error of the system is $8.956 \times 10^{-8}$ and the inverse model of the hydraulic actuator is obtained as described in equation (7).

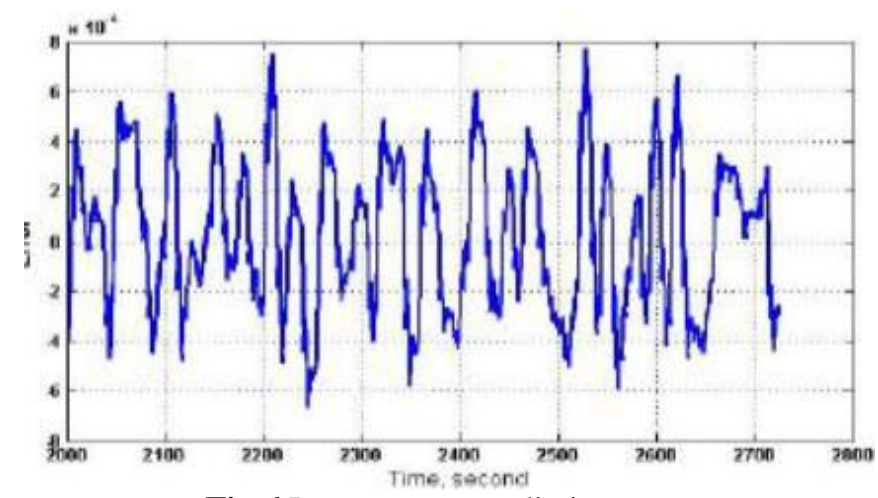

Fig 6 Least square prediction error

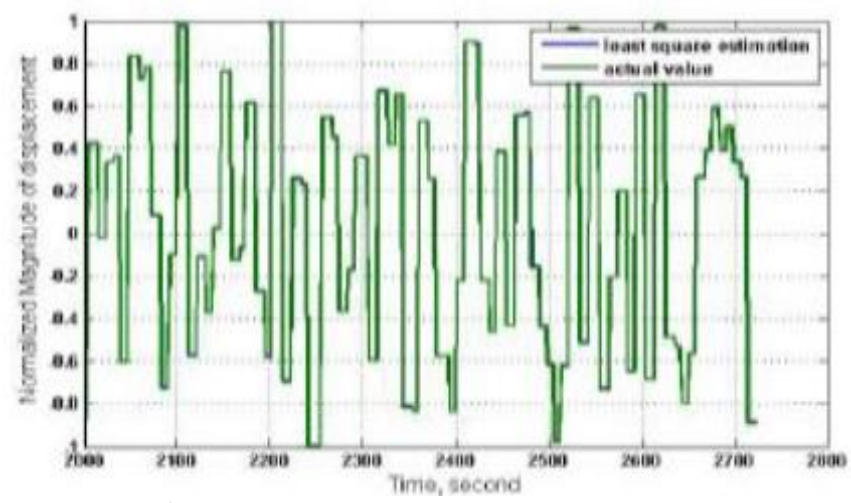

Fig 7 Least square estimation and actual

\subsection{Tuning PID Controller}

Three method of tuning PID controller has been used in this research. Heuristic method was introduced as a trial and error method with a simple and common step according to determines and decides the best value. Having his road profile of a hump and hole as a disturbance, the value of proportional gain, $K_{P}$ was set up with zero condition of $K_{I}$ and $K_{D}$. The best value of $K_{P}$ was chosen based on the lowest mean square error (mse) and settling time.

The method was repeated by set up the $K_{I}$ value and followed by $K_{D}$ value. Therefore, using heuristic strategy, the best PID controller is obtained with the best combination of $K_{P}, K_{I}, K_{D}$ of 80,10 , and 1 , respectively with the lowest mean square error of $8.4 \times 10^{-5}$ and settling time of 6.8 seconds. Figure 7 show the comparison of control system performance for P, PI, and PID controllers. In can be seen PID controller performed better than the others. In this research Ziegler-Nichols closed tuning method have been used with a simple method that uses the ultimate gain value, $K_{u}$ and the ultimate period of oscillation, $P_{u}$ to obtained $K_{c}$. The table of close loop tuning method can be shown as in Table 2. 
Table 2.Closed-loop calculation of $K_{c}, T_{I}, T_{D}$ [12]

\begin{tabular}{|l|l|l|l|}
\hline & $K_{C}$ & $T_{I}$ & $T_{D}$ \\
\hline $\mathrm{P}$ & $\mathrm{K}_{\mathrm{u}} / 2$ & & \\
\hline $\mathrm{PI}$ & $\mathrm{K}_{\mathrm{u}} / 2.2$ & $\mathrm{P}_{\mathrm{u}} / 1.2$ & \\
\hline $\mathrm{PID}$ & $\mathrm{K}_{\mathrm{u}} / 1.7$ & $\mathrm{P}_{\mathrm{u}} / 2$ & $\mathrm{P}_{\mathrm{u}} / 8$ \\
\hline
\end{tabular}

Take the sine input as a reference, the integral and derivative action was set up at zero condition. Were, a small disturbance in the loop was created by changing set point. The proportional gain value will set up by increasing or decreasing until the oscillations have constant amplitude. The value of $K_{u}$ and the period of oscillation time, $P_{u}$ were recorded. Finally, the value of $K_{P}, K_{I}$ and $\mathrm{KD}$ was determined using closed-loop table. Figure 8 shows the result of tuning PID controller using Ziegler-Nichols method. The best performance of PID controller was found with combination of $K_{P}, K_{I}$, and $K_{D}$ is $70.6,83.06$ and 15 respectively. The iterative learning algorithm is another method to tune PID parameter automatically.

Taking bump and hole input as a reference, the value of $K_{P}$, $K_{I}$ and $K_{D}$ will be tuned automatically using MATLAB coding. SoThis stopping criteria is the smallest error that can be achieved which was set to be 0.0001 for this research. Then, the program will stop if this stopping criterion is found during running process. The best value of $K_{P}, K_{I}$ and $K_{D}$ will be identified based on the lowest mean square error. Based on Figure 9, PID controller has been tuned with the final value of $K_{P}=61, K_{I}=9.1$ and $K_{D}=0.7$ and stability Overall results of the body displacement and the performance of the proposed controller's the proposed controller optimized by ILA managed to give a better ride comfort and ride handling for vehicle system because of controller strategy are tabulated in

Table 3 According to the Table 3,.

\begin{tabular}{|l|l|l|}
\hline \multicolumn{3}{|l|}{ Bump and hole road profile } \\
\hline & MSE & $\begin{array}{l}\text { \% } \\
\text { improvement }\end{array}$ \\
\hline Passive & 0.00040 & 0 \\
\hline $\begin{array}{l}\text { Active- } \\
\text { Heuristic }\end{array}$ & $5.05 \times 10^{-5}$ & 87.39 \\
\hline Active-ZN & $5.43 \times 10-5$ & 86.4 \\
\hline Active-ILA & $3.49 \times 10-5$ & 91.28 \\
\hline Sine road profile & 0 \\
\hline Passive & 0.00104 & \\
\hline $\begin{array}{l}\text { Active- } \\
\text { Heuristic }\end{array}$ & $2.02 \times 10^{-4}$ & 80.57 \\
\hline Active-ZN & $6.71 \times 10^{-4}$ & 35.48 \\
\hline Active-ILA & $1.19 \times 10^{-4}$ & 88.58 \\
\hline Random road profile & 0.00041 \\
\hline Passive & \multicolumn{2}{|l}{} \\
\hline $\begin{array}{l}\text { Active- } \\
\text { Heuristic }\end{array}$ & $9.86 \times 10^{-5}$ & 75.95 \\
\hline Active-ZN & $8.55 \times 10^{-5}$ & 79.1 \\
\hline Active-ILA & $6.95 \times 10^{-5}$ & 83.05 \\
\hline
\end{tabular}
University, 2004.
[10] J. Guillermo and S. P. Bhattacharyya. "PID

Controllers for Time-Delay Systems". Texas A\&M

\section{CONCLUSION}

The PID controller has been successfully implemented in an active suspension system through simulation study Three methods for tuning PID controller have been applied in this system. The comparative assessment results indicated that the PID controller active suspension system with hydraulic actuator using an iterative learning algorithm has performed better than PID controller using other tuning algorithms. the transfer function of hydraulic actuator for active suspension system has been identified using system identification method. Throughout the research, the passive and active suspension system has been developed and the performance of active suspension system has been proven to perform better than the passive suspension system provided the PID parameters are tuned properly

\section{REFERENCES}

[1] E. B. Walter and A. Walter, "Automotive Suspensions, Steering Alignment and Braking". American Technical.1976.

[2] H. Nijmeijer, F. E. Veldpaus, I. Besselink, Evers, and W. J. E. Schmeitz. "An Active Suspension System". Eindhoren University of Technology (Tu/e), The Netherlands,2007, pp.4-14.

[3] Y. M. Sam, M. R. Ab.Ghani, and N. Ahmad. "LQR Controller For Active Car Suspension ”. Mechanical Journal of Control and Instrumentation. 2000, pp.I441-I-444

[4] M. Kaleemullah, W. F. Faris, and F. Hasbullah. "Design of Robust H, Fuzzy and LQR Controller for Active

5] A . Kruczek, and J. Honcu. "Active SuspensionCase study on Robust Control". World Academy of Science, Engineering and Technology, 2011

7C. Tang, G. Zhao, Y. Zhang, and Y. Ma, "The Application of Fuzzy Logic Control Algorithm to Active Suspensions of Vehicles," vol. 862, pp. 855862, 2012.

6 G. Priyandoko, M. Mailah, and H. Jamaluddin, "Vehicle active suspension system using skyhook adaptive neuro active force control," Mechanical Systems and Signal Processing, vol. 23, no. 3, pp. 855-868, Apr. 2009.

A. M. A. Soliman, M. M. S. Kaldas, D. C. Barton, and P. C. Brooks, "Fuzzy-Skyhook Control for Active Suspension Systems Applied to a Full Vehicle Model," vol. 2, no. 2, pp. 85-96, 2012. M. Senthil, "Development of Active Suspension System for Automobiles using PID Controller," vol. II, 2008.

X. Shen, and H. Peng, "Analysis of active suspension system with hydraulic actuators". School of Mechanical and Power Energy Engineering, Shanghai Jiao Tong University. Proceeding of the IAVSD conference, 2003. 


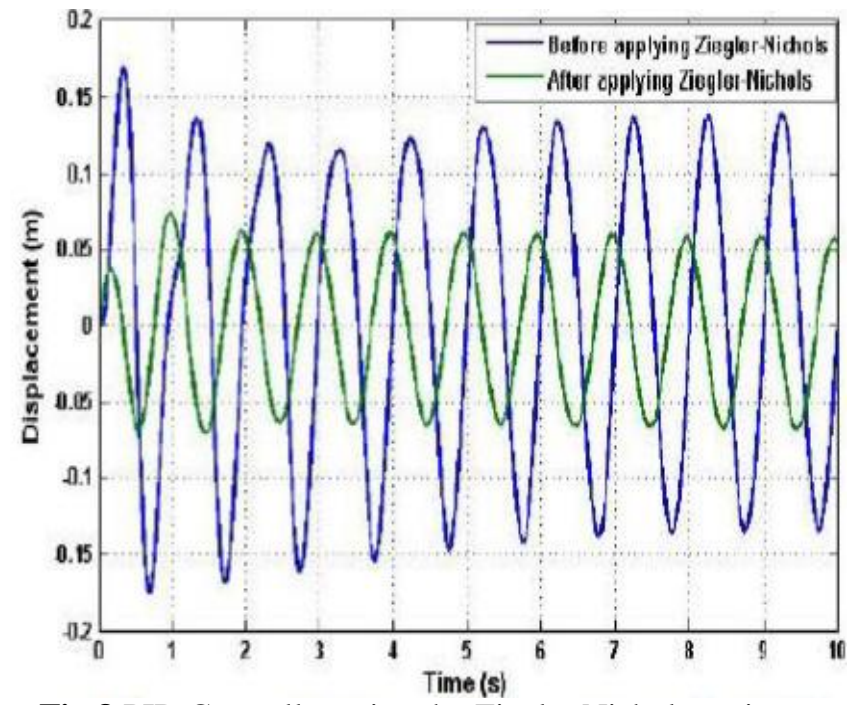

Fig 8 PID Controller using the Ziegler Nichols tuning method

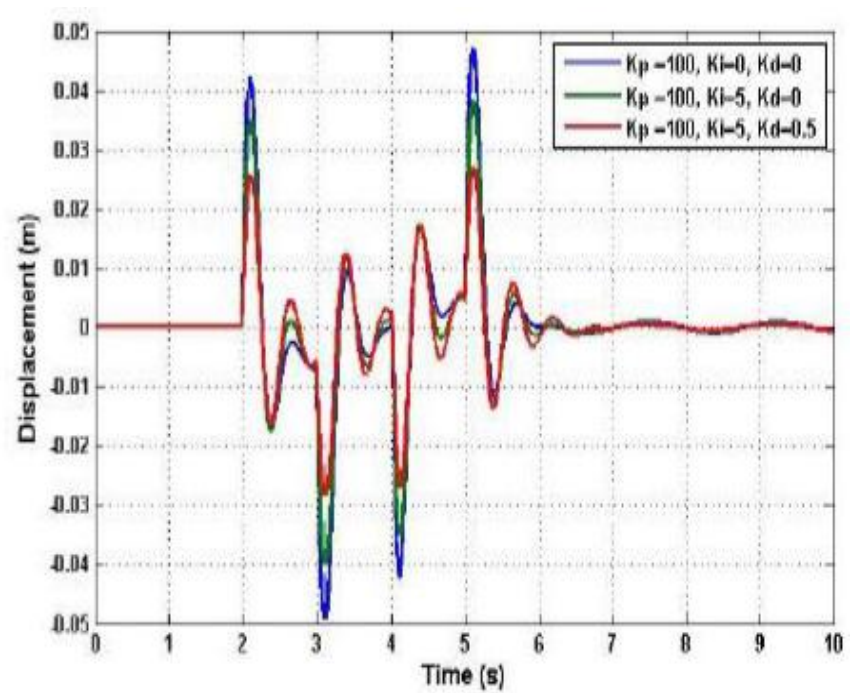

Fig 9 PID controller using heuristic tuning method

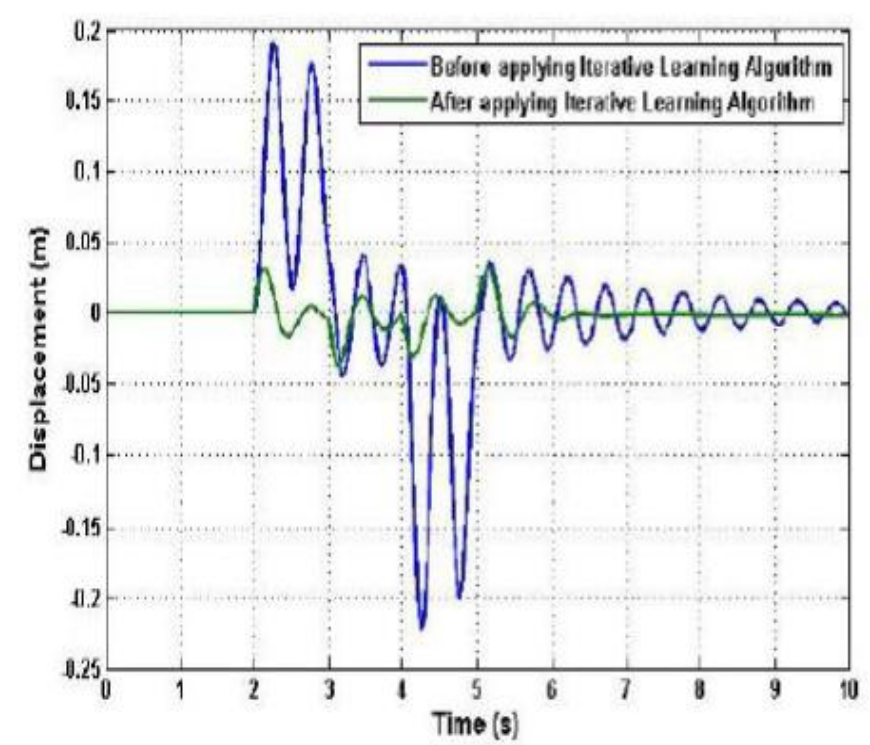

Fig 10 Body displacement for bump and hole input

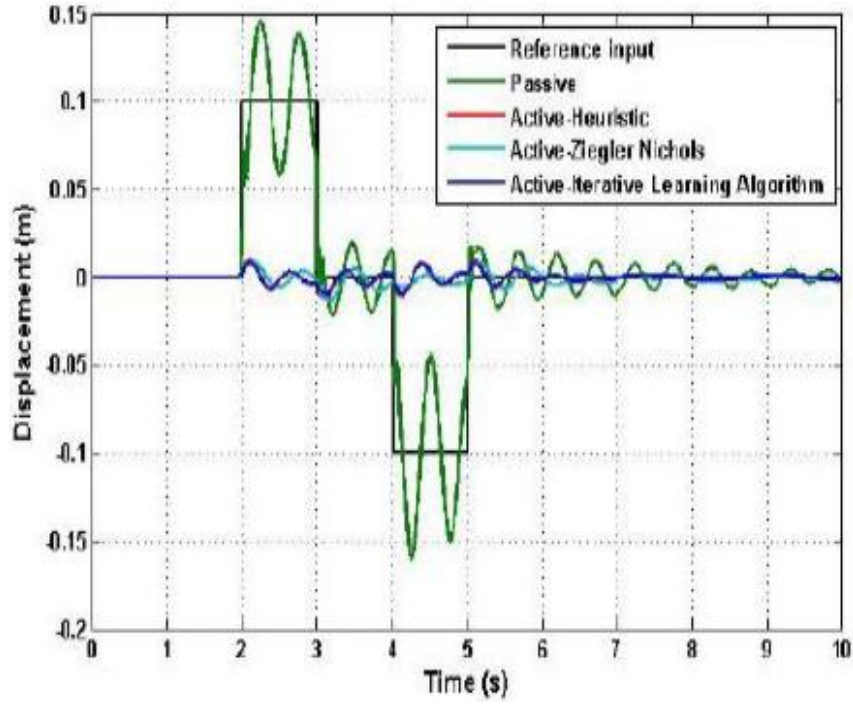

Fig 11 PID Controller tuned using ILA

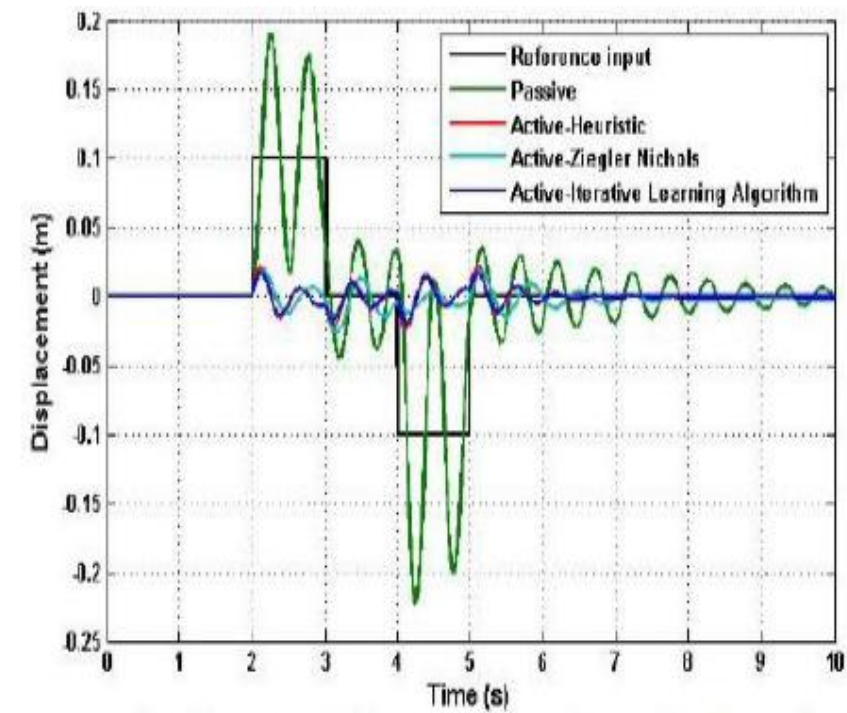

Fig 12 Rear Wheel displacement for bump and hole input

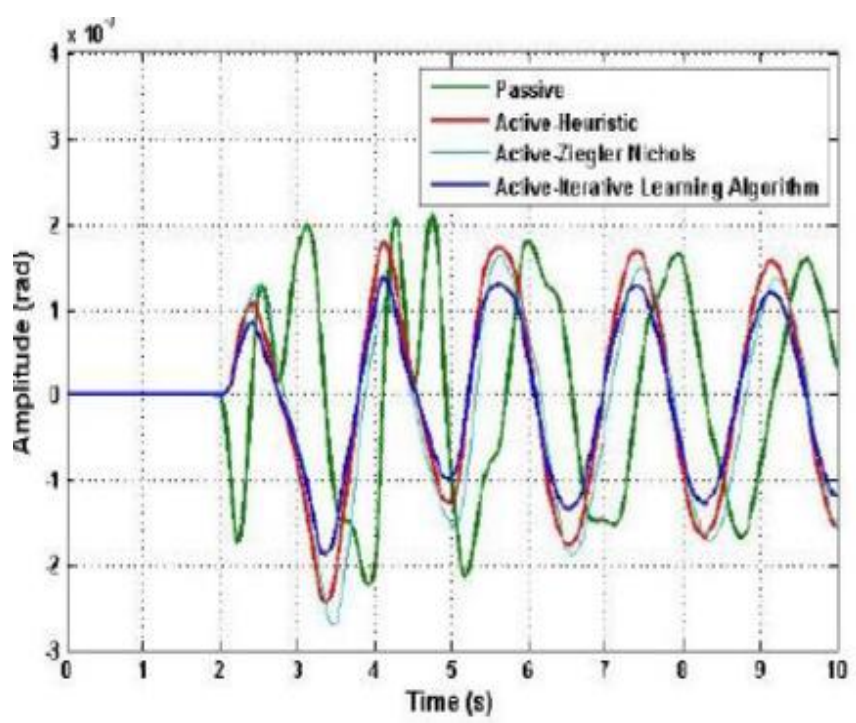

Fig 13 Degree of pitch for bump and hole input 


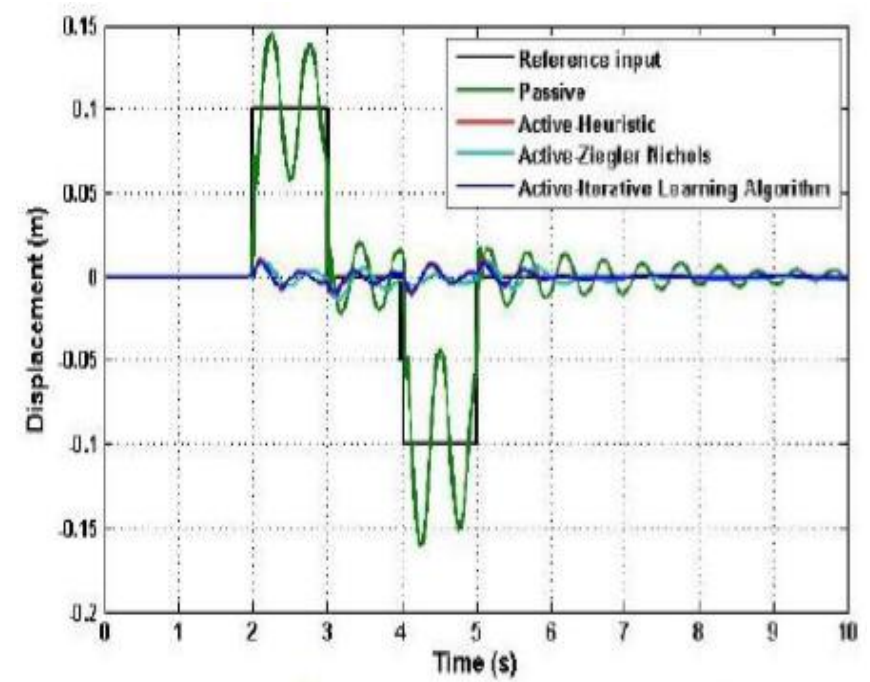

Fig 14 Front Wheel displacement for bump and hole input

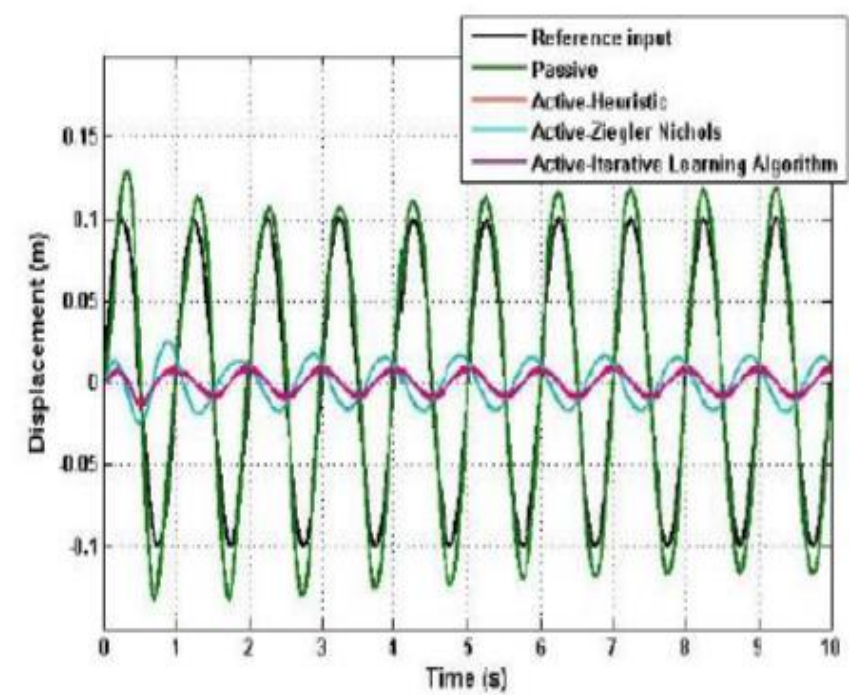

Fig 15 Front Wheel displacement sine input

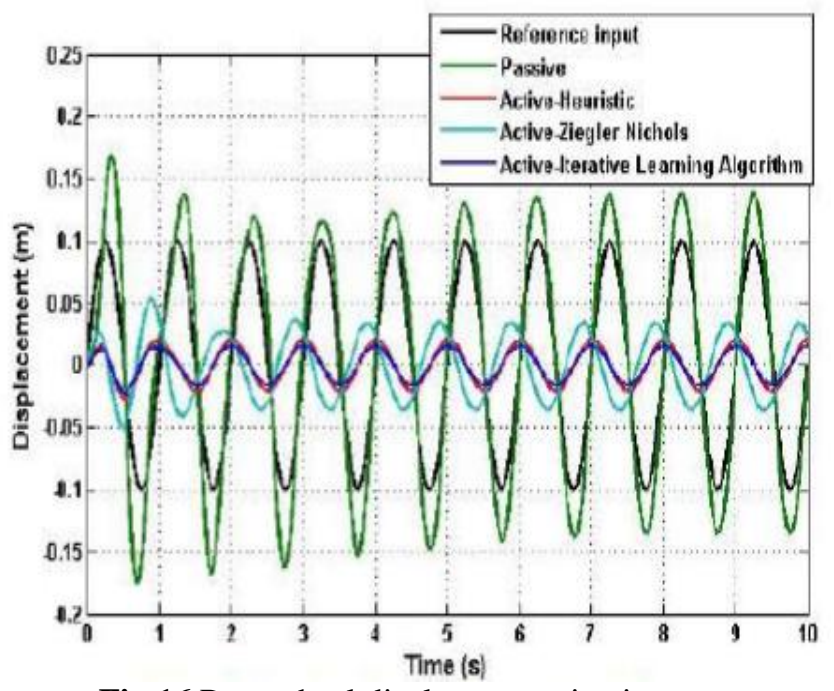

Fig 16 Rear wheel displacement sine input

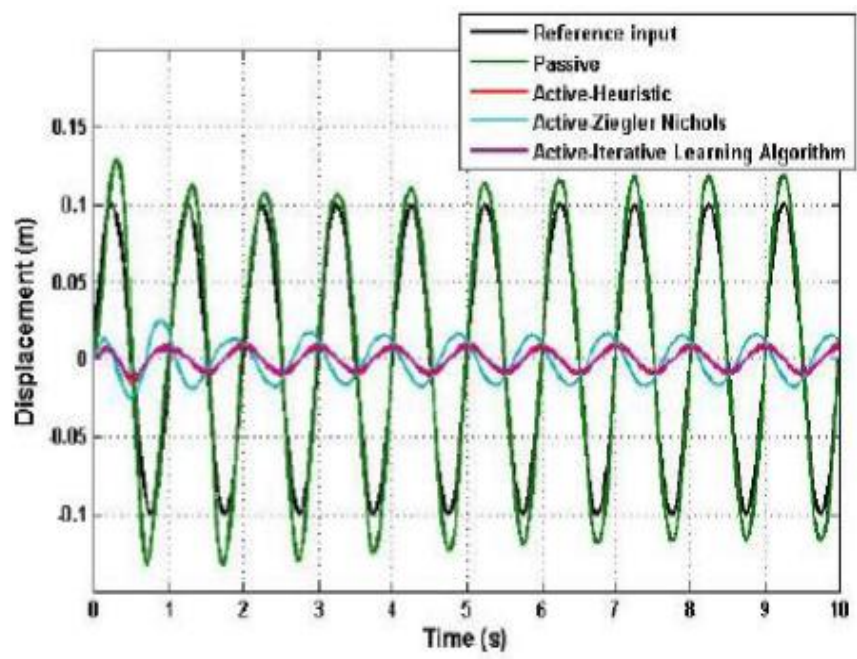

Fig 17 Degree of pitch sine input

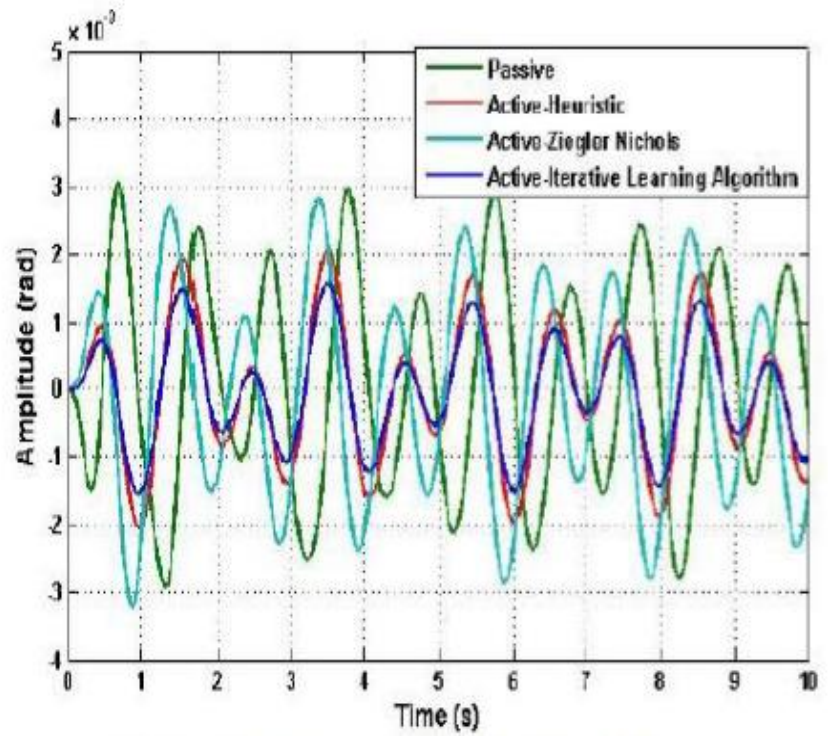

Fig 18 Body displacement random input

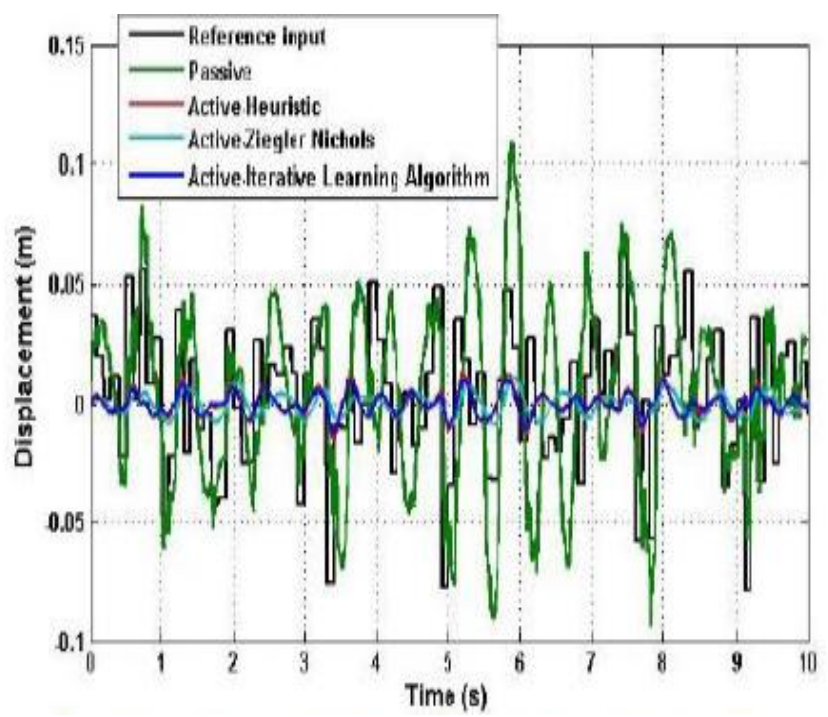

Fig 19 Front wheel displacement for random input 


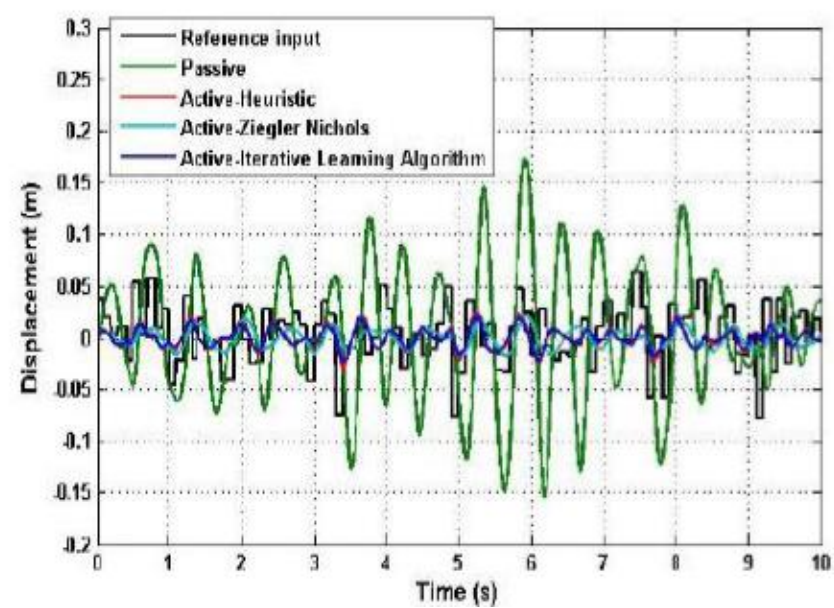

Fig 20 Front wheel displacement for random input

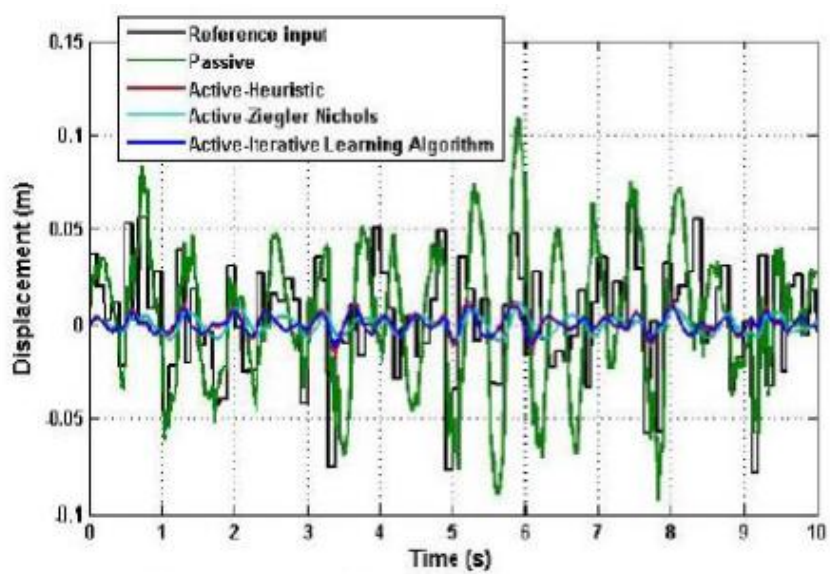

Fig 21 Rear wheel displacement for random input

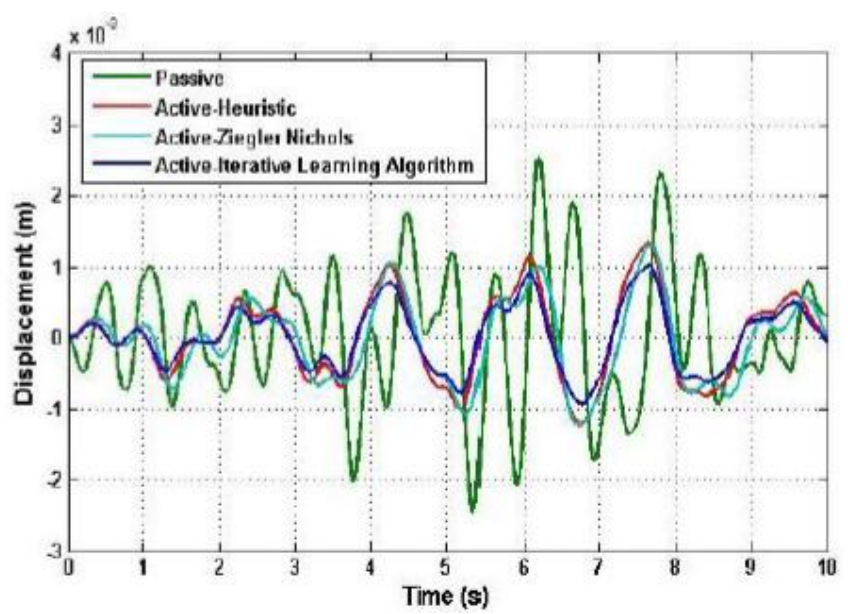

Fig 22 Degree of Pitch random input 